\title{
sciendo
}

DOI: $10.2478 /$ rjp-2019-0014

Rom J Psychoanal 2019, 12(2):15-37

Rom J Psychoanal

\section{THE REGRESSIVE MAGIC OF WORDS IN PSYCHOANALYTIC TREATMENT}

Irina Adomnicai ${ }^{3}$

\begin{abstract}
The clinical vignettes evoked in this text open up, I hope, new lines of thinking and reflection, necessary in approaching the following fundamental issue: what does the archaic aspect of the analytic relationship consist of, considered a determining element for the changes and transformations induced by the psychoanalytical protocol? An indispensable question for the deepening of means of evolution for the psychoanalytical technique, directly determined by the diversity of personality structures and defence mechanisms which the method has been confronted with the past years. All the more so that what can be brought to light from the past never represents a faithful witness of the prehistoric age, but rather a heterogeneous product to the extent that every stage of life traversed by the human subject modifies in its turn " primitive " experiences. This is also the reason for which states of pathogenic regression do not allow an exact reconstitution of original situations. Especially since there is not much said about origin. Only the paradox can be noticed, that the origin is different from the archaic. An archaic that continues to produce meaning in the present, forcing psychoanalytical practice and its practitioners to adapt to modernity, thorough the strangest and most unexpected clinical forms thus convoked.
\end{abstract}

Keywords: archaic, verbal regression, psychosomatic regression, transference, countertransference, psychic economy.

\footnotetext{
${ }^{3}$ Paris Psychoanalytic Society; irina.adomnicai@gmail.com
} 


\section{Introduction}

As opposed to all other forms of therapy the psychoanalytic cure mobilizes the archaic aspects of language, establishing thus a regressive dynamic that incited the significant to reveal its primordial form of representing the ultimate essence of the unconscious psychic tissue. The word, which, as all psychic action, cannot escape the dominance of the all-powerful principle of pleasure-displeasure, becomes in this perspective the main instrument for the investigation of the method. In its turn free association allows transference, an intra-psychic and intersubjective phenomenon, to reveal the archaic emotional fund constituted by infantile sexual experiences updated in the analyst-analysand relationship. An unavoidable economic determinism, the regression of language and spoken words from the representation of a word to the representation of something, meaning the image, within sessions of psychoanalysis defines the way in which varied means of communication, from the most primitive (extralinguistic) sensations, gestures, psychic, corporeal, somatic feelings, to the most sophisticated, can be found, built or rebuilt throughout psychic treatment.

Freud introduces the notion of archaic in psychoanalysis in 1915, when he forwards the hypothesis of « original phantasms », a collective inheritance transmitted phylogenetically. In this new theoretic perspective, the original repression represents the symbol of the archaic, manifesting under the paradoxical double-aspect of cause and absence. Situated from the start in the logic of the historical and archaic processual continuity, these structural elements of a symbolic order, present in the psychic organisation of all human individuals, constitute the basis on which the process of formation of personal phantasms was founded, determined by the individual historical experiences. The difficulty of thought for this point of view is that, although Freud denies the theory of seduction, underlining the role of infantile phantasms, he continued at the same time to search for and demonstrate the existence of the archaic event that occurred in reality, as an event susceptible to be verified. The scenes transmitted phylogenetic became the primordial fundament of original phantasms, which also offsets the issue of the reality of the primitive scene. In this way the event-character of the primitive scene sees itself transferred in a structural dimension, which involved the movement of the ontogenetic causal axis on a phylogenetic plan. Jacques Lacan took over this Freudian historical-structural articulation in a clinic perspective, underlining the structural dimension of the Oedipus complex, with the purpose to halt discussions on pre-oedipal stages, replacing them with pregenital stages. In psychoanalysis, with M. Klein, Winnicott and Bion, a period of fascination for the archaic, a concept that turns from a point of view of psychoanalytical technique into a search for ways to adapt the setting, in the idea of obtaining from non-neurotic patients, more or less regressed, information and clinic evidence in regards to their most profound and longburied psychic experiences during the session. M. Klein, who J. Lacan remarked as being a 
genius, opened the path towards the knowledge of the " archaic Ego », for which the role of projection and projective identification were predominant, mechanisms of primitive defence of the patient who, in the continuous and futile struggle to individualise himself, has difficulty in distinguishing what belongs to him and what is coming from the object. The clinic case that serves as a red thread will allow us, hopefully, to identify the main parameters of the archaic manifestation in actual psychopathology.

\section{Psychoanalysis/Psychosomatic: an alternative at the frontier of the archaic?}

Luiza called to set up a meeting and insists on telling me from the get-go that she had obtained my professional contact information through the institution which had offered her a free consultation. I would find out later that "she picked my name", the only "foreigner" among the three offered by the secretariat at the suggestion of the consultant. The feeling of urgency that emitted from our conversation makes me represent her in a state of intense agitation and excitation. When I see her for the first time I am surprised by her juvenile aspect, by her harem pants and her billowing top that modify her appearance and make her seem plump, when in fact she is nearly skeleton-like because of a severe anorexia. Preliminary meetings are the occasion of incessant complaints. The sufferings endured from the first moments of life to the present, appear to be all caused by her body. A body described by Luiza as a true persecutor, which did not leave her a moment's rest. She never remembers being healthy. Somatic symptoms are declined in the monotonous rhythm of an endless litany: severe asthma, at least 7 bouts of conjunctivitis per month, allergic rhinitis resistant to any treatment, gynaecological problems that the patient did not speak to the consultant about because he was a man, but which she would not discuss with me either for a long time, cold sores that recur periodically, eczema, eye problems, and especially a chronic fatigue that causes episodes of unpredictable numbness at any time of day and no matter where she is. The doctors diagnosed a narcolepsy, which would have nothing to do with the chronic fatigue syndrome. It is only at the end of the list of all these problems that Luiza will talk to me about the earliest and most dangerous symptom, an infant anorexia that lasted until the age of 11-12 years. She points out that what healed her was not medical treatment, but an entirely fortuitous event. The separation from her mother, who had been forced to leave her home for three months and had to leave her in the care of an aunt. Her aunt and uncle kept a restaurant and it was there, Luiza recounts, that she found out what an appetite meant. She began dining on beef and pork chops, specially prepared for her, and all food problems were soon gone. Looking me straight in the eye, Luiza asks if I think her mother could ever feel guilty for having a child sick all the time. Before I was able to ask what she was thinking about this, Luiza immediately added that around the age of 11-12, when her anorexia disappeared, she began to have very severe asthma attacks. Several times she was even admitted to hospital in a situation of borderline respiratory failure. For some time, anorexia and asthma 
alternated repeatedly, increasing her mother's anxiety and depression. Luiza insisted that she had always refused doctors' proposals to do psychotherapy, because she did not understand what it would be useful for. If they had not been able to cure her with all their medicines, how could words help her? However, she did not reject the proposal made at the Institute of Psychosomatics, because, as it was not psychoanalysis but psychosomatics, it seemed reasonable to accept it. I then intervene for the first time and ask how she imagines the difference between psychoanalysis and psychosomatics. She answers me without any hesitation that the specificity of psychosomatics is "listening to the body". I speak again and ask her how she imagines a psychoanalyst (I call myself a psychoanalyst and not a psychosomatic specialist, both to remove any medical reference, and to introduce the paradox) such as myself could "listen to her body, affected by years of suffering to which the doctors found no cure". To my astonishment I hear her, very sure of herself: "well, with words". I commit myself then and propose to her: "If your body needs to be listened to with words, I think we can start psychic treatment".

\section{An extraordinary conversation}

"What are the two doing together?" Freud asks an imaginary interlocutor. The answer: "speaking". Certainly, but although their conversation is similar to any other, to the extent that communication is done through words and silence, what happens to each of them far exceeds what the analysand and his analyst think they can control and determine. And this is not surprising because events, feelings and thoughts kept secret until then, would be discovered and witnessed in this inter-action, something that happens more or less in each psychoanalysis, but especially because the specificity of the analytical setting allows and even favors the appearance and expression of the unknown. There is an unknown that can surprise the analysand and the analyst in an unexpected confrontation, whose peculiarity is that of reviving the silent language of the "archaic child", the infans. But this is an unknown that can manifest its presence only in the moments of joint regression of the psychoanalyst and the analysand, moments when both perceive the "archaic infant" in the same way and in a different way. The fact that the psychoanalyst listens to his analysand in silence establishes between them a mode of resonance that enters into agreement with the original silence of the archaic child, the one who does not speak yet. In these moments of regression, the analytical couple works in an animistic record of reversal, the analyst becoming the archaic child who listens to the speech of the adult analyzer, without understanding very well what he is saying.

Only in this way, argues J.C. Rolland (2005), the analyst can distinguish echoes from the "other scene", the unconscious scene that the patient's conscious discourse tries to keep hidden. The infantile then has a chance to finally be heard. The infantile that this author defines 
as an ensemble consisting of affect and representation, inherited by a child from its predecessors. In this sense we can consider that the infant represents all the traces left in the formation of the self by trans-generational inheritance, through identification and dependency relationships. Living vestiges, archaic and at the same time current, they play a major role in the creation of the subjective register of the human individual.

For a long time Luiza has a very strong resistance to any of my attempts at installing a treatment setting compatible with a regressive dynamic. The ritual that she puts into practice, from the very first session, incites me not to offer her the sofa but a seat with a face to face position. Luiza rejects my proposal of two sessions a week, under the pretext that it would be too expensive and that she is "stingy". The significant "stingy" will take shape at different levels (somatic, corporeal, psychic), thus allowing, through the new senses gained, a marked improvement in these three operating registers. Meetings always start the same way: Luiza sits in the chair, looks for her glasses, wipes the lenses with exaggerated care and attention, repeatedly blinks her eyes, and at one point begins to fix me almost without blinking all throughout the session, for 45 minutes. This whole scene is punctuated by compulsive yawning, for which Luiza profusely apologizes. Her need to control everything - the space, the analyst, the setting, her sickness, her weakness, the negligence with which she dresses in clothes that could be worn well by a boy - at first made me seriously doubt my chances of being able to help her. All the more so that, shortly after the beginning of psychotherapy, I was informed of a gynecological problem, about which the patient had not spoken to the consultant. Luiza then tells me, in a seemingly indifferent tone, that around 15 years ago during a gynecological consultation she and her mother found out she had a genital malformation, a double uterus and a double vagina. It took her 9 years to accept the resection operation for the membrane that divided her vagina. I draw attention to the fact that she came to do psychotherapy immediately after this intervention. She tells me that it has no connection and that it is just a coincidence. She added that she had difficulty accepting the operation for the vagina, but that she refused the uterine intervention, because she did not intend to have children. She considers it a real injustice that women must bear the burden and birth of the child. She hoped with all her heart that scientific advances would enable men to take on this function. But here was the first time that an incidental came up in Luiza's speech. She remembers on this occasion that at 11-12 years, so during the pubertal period, she returned from a holiday colony with a tick on her torso. She cannot forget the feeling of terror in which she lived until it was taken off. The high warning sign shouted at me in a psycho-dramatic way: "And the tick didn't grow!" This attempt to open up to infantile sexual theories will be quickly abandoned under the pressure of repetition, and the patient will resume the cycle of somatic complaints, enriched by several new symptoms: a sudden loss of visual acuity, sufficiently worrying for the ophthalmologist to prescribe an examination, repeated sinusitis, painful pinching sensations of the clitoris that prevent her from putting on her underwear and sitting in the armchair during psychotherapy sessions, seizures of 
eczema, especially on her neck and torso. From all this generalized bodily excitation that Luiza addressed me endlessly, a question ends up unleashing my great wonder - "How is it that, Luiza asked herself, she who does not know sexual desire and masturbation, has always had a boyfriend since she was 14 years old?" "Some kind of double?" My question surprises her enough to tell me, after a moment's thought, that I might be right. Especially when it came to Emanuel. She preferred him to everyone else because he had the biceps of a truck driver and soft skin. She remembers doing bodybuilding daily, until she managed to resemble him. "Bisexuality fascinates her because she finds homosexuality more logical than heterosexuality" (a disturbance in the course of thought?). "Men with men, women with women". I listen to her telling me that, since the age of 14 , she has never been "single", although she hates penetration. She praises herself as a "great expert in masturbation" and that this must explain why she has never been without a boyfriend. The more I listen to her, the more I portray her functioning as a typical borderline pathology. And I also remember that the greatest difficulty in understanding the problem of borderline cases comes from the complexity of the structure that determines at the same time the polymorphism of the symptoms, the different forms of anguish and the multiplicity of defense mechanisms that try to cope with them. The state of intense arousal, almost impossible to calm, that Luiza addresses me is caused by a double unconscious affect, of intrusion and/or abandonment. She is the victim of a permanent confusion between the self and object impulse, between the erotic and aggressive impulses, between the auto-erotic impulses and drives whose satisfaction requires the intervention of the object. The archaic ego becomes the engine and center of this confusion caused by the pulsational pressure and the impossibility to find the original oedipal objects. Like Sisyphus, the patient constantly reiterates the impossible attempt to make her desire coincide with the object she addresses it to, disappointed that it can never be anything other than a substitute.

\section{Transference: the path on which the archaic is updated in the language}

Freud has continuously stated that nothing ever disappears from the first experiences of the human individual. The unconscious keeps the inscription of primitive psychic mechanisms and updates them as soon as an opportunity presents itself, such as in transference for example. As psychoanalytical experience proves during the course of treatment, transference is an extraordinary instrument of remembrance (J.C. Rolland, 1994). Consequently, the analytical discourse appears saturated by the archaic. Either because it tries to explain the second phenomenon through the first one, or, in trying to justify the second time, it deepens its analysis until traces of the first moments are found within it, or because in treatment the effect of the "après-coup" is linked to a process from before. What is verified both logically and experimentally is the existence of a necessary correlation between the present and the archaic. Moreover, psychoanalytic practice currently illustrates the action of the archaic in the present. 
The theoretical-clinical perspective in which the archaic represents what never ceases to produce effects, whose causality remains inscribed in the unconscious revealing itself only indirectly, through symptoms, which can only be understood and treated by the psychoanalytic protocol. What does the archaic relationship consist of? We could say that it is defined as a relation of dependence on the primary objects. When the child internalizes this experience of addiction in an atmosphere of affection and care that parents provide, then the agency of the Superego will metaphorically symbolize "the protective powers of Destiny", as Freud stated.

Unfortunately for Luiza, fate did not reserve this optimistic version for her. Her "narrativerecitative" speech (A. Green, 1992), whose narcissistic valences of a defensive nature were meant to exclude me from the relationship, ceaselessly repeated the same obsessive story. The story about an almost non-existent couple, with a father who left his family a year after her birth, and a mother scared of a newborn, who, from the first moments after birth, rejected her by strongly refusing to be breastfed or drink milk with the bottle. But early anorexia, which miraculously disappeared when Luiza was alone with her uncle and aunt, hid a deeper and more painful grief. As I will find out later during the analysis, the genital malformation my young patient suffered from proved to be a direct consequence of Distilbène (Diethylstilbestrol), a drug against sterility prohibited today because of the adverse effects caused during the embryo's formation. This Distilbène had been prescribed by Luiza's gynecologists, because she could not get pregnant. One more reason for her to feel fate was unfair. For three years, psychotherapy developed in this atmosphere of violent reproaches against her parents and against me in transference, where I was also perceived as unable to offer her what she expected from "psychosomatic treatment".

From a counter-transference perspective, I was feeling increasingly discouraged. During the sessions, Luiza was limited to the external reality and categorically resisted any attempt on my part to put this material reality, of which she complained continuously, in the perspective of her mental reality. Thus, she placed me in the exclusive position of a witness, a strategy that I understood as a defense mechanism against the danger represented by the ability to unlock associative language. In this dynamic I also wondered if the patient did not risk a decompensation in case of regression - a situation in which the image of the Ego and the corporeal scheme that served as figuration could have been in danger of fragmentation. I relied in formulating my hypothesis on the "narrative-recitative" character of the patient's speech, a defensive discourse whose unitary aspect prevents any manifestation of the latent plan. At the same time, I find it interesting to point out that the narcissistic valences of this discourse, which we have already mentioned, played a functional role as paraexcitant, a role that should have been ensured by the psychic apparatus of the primary object from early childhood. The particularities of the patient's speech in the session, as well as the fact that during the first three years of psychotherapy dream activity was practically absent, have comforted me in my 
decision to propose to her the face to face position. Although the dream may represent a fulfillment, an accomplishment of the unconscious desire, in traumatic circumstances a dream could manifest itself in its most rudimentary form, in preparation for the installation of the principle of pleasure. The classic example is nightmares, in which situations of fear, fright, persecution, pain or failure are repeated, which illustrates how melancholic manifestations orient the psychic activity towards a deadly identification with lost objects, also illustrating the place occupied by the dream activity in the process of mourning. The rare dreams that Luiza ever speaks to me of are nightmares, whose content endlessly repeats the same scenario: Luiza feels in danger and for this reason barricades herself in a room. She secures all the locks on the door and windows. But once this action is completed, she realizes that the danger actually comes from within and not from outside. She fights against the evil with all her might, but the enemy wins the fight every time, and in the end it manages to destroy her.

Denise Braunschweig hypothesized that "psychosomatic" patients would have remained attached to the "reality ego from the beginning", and would not have reached the development phase of the "pleasure-purified ego". Luiza complains of growing vaginal pain during sexual intercourse. She reproaches me that psychotherapy made her want penetration, but that the sensations felt were not pleasant at all. One night after a strong contraction, Luiza is brought to the hospital. Exasperated by the patient's complaints and her inability to help, the gynecologist prescribes vaginal kinesiotherapy sessions. From that moment on, Luiza speaks of nothing else in the session, other than "vaginal psychotherapy". Listening to her as she describes to me in detail what her muscles do during her vaginal massage, the thought that what she cannot represent, with the help of phantasies, returns to her from the outside through the perception of images projected on a screen appears to me, and I say: "The second session of psychotherapy with kinesiotherapy". She replies: "It is a complementary gymnastics exercise. When words have no effect, then one proceeds to action". Fuelled by a negative countertransference, which in this context of rivalry with the physiotherapist I cannot manage to control, I find myself answering: "Because psychic conflicts are solved through gymnastics exercises?" Despite relaxing kinesiotherapy sessions, contractions are becoming more and more frequent and painful. More than that, they are associated with a new symptom, a sensation of "burning and itching at the level of the clitoris, exactly at the border between the outside and the inside", Luiza said. Disappointed with the result, the gynecologist ends the sessions for vaginal relaxation. Luiza, puzzled, asks me "where do these vaginal contractions that make her suffer come from?" "Maybe from the fact that you do with your vagina as you do with the anus, that you give it the same location and the same utility". I tried by my interpretation to introduce the infantile sexual theory into the preconscious material of the session. I am surprised by the speed and affective tone with which the patient appropriates my interpretation, in a true insight. 
Luiza tells me she doesn't know why, but my words make her think about how she is "stingy". (I draw attention to how in French "stingy" is called "grippe-sous". This signifier will play a major role in the treatment of the patient). Luiza says that since she was little she never spent any of the pocket money she was given, "not even to buy herself a candy". She saved it because, since then, she was planning to buy an apartment for when she would leave the house she lived in with her mother. She still can't imagine today that she could pay rent to an owner who would benefit in this way from her money. Bank loans are not the same thing. Even if she gives the money back with interest, in the end she also makes a profit, because the good bought in this way becomes her exclusive property. As I listen to her, I make an instant connection between what her infant anorexia tells me, and I propose the following interpretation: "Yes it is true, only in your system you do not give anything, but you do not take anything either". No association took over to work through my intervention, but shortly after Luiza tells me about the first dream that is not a nightmare. A dream of transference in which "the purified pleasure ego" began to emerge from all the negativity that occupied the psychic scene so far. Luiza is in an unknown place, in what seems to be a room. The room has an open window. A man she doesn't know is present. She has the feeling they are both in danger, without knowing why. The unknown man barricades the door, but has no time to close the window. The witch is already there. Luiza marveled that, although the window remained open, the witch did not try to enter. Her appearance surprises her: long silky blonde hair and bright blue eyes. She seems derisively dressed in all pink, pink dress, hair bow, pink shoes, carefully done up, a real "Lolita", "the peak of ridiculous femininity", comments Luiza with disdain in her voice. But despite her pleasing appearance, she knows the witch is dangerous. That's why, to prevent her from doing any harm, Luiza approaches the window and begins to sing a song she likes a lot and often listens to at night: "One more baby". She asks if I know it. As I do not answer she carries on. The witch begins to sing. What was surprising, Luiza adds, is that they were in perfect tune with each other. Singing together was becoming an extremely pleasant thing. The patient repeated several times that she was feeling very good in this dream, and that she had the indefinable feeling that something very important to her was happening at that moment. She even remembers saying in his dream that it sounds ridiculous, but that the answer to all her problems will come from the "pink-feminine" color. As curious as it may be, Luiza insisted, this morning she woke up with the same idea in mind - that from the color pink, which she always hated, the solution of all unresolved medical problems will come. Listening to her, I tell myself in my inner speech that it was time to ask her to sit on the sofa and come to three sessions a week. The work-through allowed by the dream work proves both the intuition of Luiza that the child helps a woman to become a mother, as she is the first to sing in the dream, and it shows that she understood, in the true sense of the term, my previous interpretation, that she "gave nothing, but also took nothing". 
The emergence of the ability to dream in treatment radically changes the psychic position of the two partners, to the extent that the dream story circumscribes a transferential space unknown until then. The figurability of the dream images lived by the patient and the analyst separately, as well as the jointly realized figurability, give the invisible character of the unconscious a visibility in images, which constitute an immediate sensory mode of communication. This type of archaic communication, called empathy, consists of a phenomenon of mutual identification that includes an action of transformation of the interlocutor in the information thus transmitted. Only if the analyst accepts to be involved in such an exchange of images, ideas, feelings and sensations of all kinds, the unknown meaning carried by the silent language of the images can be expressed and translated into words. The transfer thus reveals its animistic characteristic, a magical operation illustrated in the treatment by the conjuration of psychic appearances and disappearances. Since the discovery of transference until 1938, Freud himself never stopped questioning the fact that the patient reincarnated figures from the past in the person of the analyst.

\section{In the pulsational cauldron of metapsychology}

The passage from the armchair to the sofa deeply changes the patient's relationship with the psychoanalytic setting and method. Luiza reproaches me for the emptiness she feels when she lies on the couch. She mainly complains about the fact that in the seat before, my office with the objects around her, the books in the library, the paintings, the carpets, the trinkets, the flowers, always fresh, helped her calm down and find topics to talk about. Since lying on the couch, she feels as if I have put up a mirror and left her alone with the reflection of her image, which always disappoints her and makes her unhappy and insecure. I understood then that until the moment the setting was changed, my cabinet was the only narcissistic projection support for the elements of an archaic topic. The change of position created a situation in which the possibility of installing regression forced me as an analyst to assume a true splitting of my body. A body whose maternal valences will symbolize, from this moment on, the emergence of an intimate space capable of containing the patient's body and psyche. An intimate common space that throughout the treatment becomes the projection surface of an archaic topic finally subjected to the principle of pleasure. This narcissistic support for the projection of the archaic will determine the dynamics in which the original differentiation of the Ego from the Id is repeated. For the unconscious, which does not know the passing of time, these surfaces for the inscription of archaic ghosts will become privileged means of figuration. Despite her resentment towards the newly established setting, psychic treatment will allow the patient to move the archaic conflicts, in which she is unconsciously trapped, from the corporeal space to the dream space. I would like to draw attention to the fact that Luiza was not confronted with the classical analytical setting, so I did not disappear from her field of vision, except when the 
dream work proved that the principle of pleasure finally dominated the destructive alternative of displeasure. The patient finally had access to the representation of the maternal object as a total object and to ambivalence. Freud argued that only the subject's possibility to represent the loss of the primary object allows the establishment of the principle of reality, thus placing the negative as the origin of the thought and symbolization process. In the article dedicated to the negation/denial Freud proposes that the "condition of existence" and "proof of reality" are based on the necessary condition that "objects that have achieved a real satisfaction" should be lost.

This implies, among other things, that the subject succeeded in the process of mourning the "primal sensation" regarding hallucinatory satisfaction. Yet, as it appears from the anamnesis, Luiza invests the maternal object in a negative way from the first moments after her birth. She refuses the breast and even the bottle, while also proving precocious in the acquisition of sphincter control, walking and speech, in a word autonomous from the beginning, as if she needed to deny at any cost the need of dependence on the primary object. A "prematurity of the Ego" in M. Fain's definition, which led to a pulsional disintegration in the libidinal plane, responsible for the many somatic symptoms, some very worrying such as asthma and anorexia, others more mysterious for the doctors consulted, probably because they were psychosomatically over-determined. The session materials will allow us, I hope, to penetrate the patient's feelings and experiences from very long ago. From that time before the acquisition of the language, which could be perceived, represented and formulated in words thanks to counter-transference. The transference-counter-transference dimension of the archaic relationship can be experienced in treatment only when the analyst begins by assuming, and then analyzing maternal transference. In this clinical-theoretical perspective I represented Luiza's refusal towards femininity and motherhood as an attempt to exorcise the danger of the archaic's return to the present. One of the first dreams recounted during the sofa treatment illustrates, with an impressive dramaturgical acuity, this problematic of losing the primary maternal object. Luiza is again in an unknown place. A "strange" place, "saturated by a colony of rabbits to the point of nausea". There were many, of all sizes, from the largest to the smallest possible, from the most beautiful to the ugliest. Luiza was wondering what she was doing there, when suddenly her eyes were drawn by a small wounded rabbit. He had "the skin of its belly torn deep". The wound was so deep that all internal organs came to the surface, invading all the surrounding space. She woke up from the nightmare, Luiza underlined, "wet with sweat". I evoke again out loud the dream image and her formulation, "a colony of rabbits". Luiza starts laughing and tells me that this expression makes her think of her father (in French the expression "chaud lapin" means a philandering man). She evokes with anger in her voice that her father left the family home a year after she was born, and that since then he had three relationships with women he never married, but with whom he has had 5 children altogether. After a moment of silence, she added in a fit of laughter that resembled crying: "They breed like rabbits". 
Beyond this frightening, exciting and fascinating primitive scene, I also discover in the regressive condensation revealed by the dream work, a mother-daughter relationship both fusional and destructive. As I was to find out later, the dream rabbit represented the analysand's transitional object. A stuffed rabbit toy, the belly of which Luiza cut with scissors as a child. Listening to her I formulated, in my inner discourse, the interpretation that this rabbit represented her and her mother in a hyper-condensed manner, in a deadly archaic report of reproduction through parthenogenesis.

The patient interrupts my thoughts with a memory, one of the "only happy ones" experienced during puberty and adolescence. Between 12 and 19 years of age she had coadministered with her mother a "summer vacation" colony (camp) for young children. She adds with nostalgia: "As a truly competent and responsible couple". As she has been planning to move out of her home since she was born, Luiza is worried about how her mother will handle herself alone. She also marvelled at the deep attachment she discovers she feels towards her mother, and which she did not realize until it emerged in the analysis. I am reminded of case studies (R. Perelberg, 2017), in which female analysts report the specificity of the problem of mourning work regarding the loss of the primary maternal object, in the psychoanalytic care of women, led by same-sex analysts. The archaic character of this type of difficulty would be due to the persistence of a melancholic nucleus highlighted by the transference-countertransference dynamics, whose content, a relentless primary love, is exclusively expressed through somatic symptoms. Named for this reason psychosomatic, these manifestations are the expression of the archaic connection with the origin, and explain why the evolution of the female child can take on the frightening characters of partially-fragmented objects. Luiza excitedly informs me that she has found work as a journalist paid by the line. An occasion that excites her even more because she was given the opportunity to correct a book titled "Sex toys". Falling prey to a state of arousal that worries me, but which Luiza does not realize, she tells me that she has discovered in this way the existence of sexual gadgets that fully correspond to the image she has always had of sex, but that she has never shared with anyone before. Shaped like animals, plants, vegetables, birds etc., these objects of variable texture represent in their diversity one thing sex. As she was offered a few samples, she tried them all and was delighted with the effect. They were beautiful and pleasant to the touch. But most important to her was that these samples did not evoke the male genitalia as they were not phallic, but more round, being neither feminine, nor masculine. Luiza feels confused, does not know how to explain what she would like to say. In the face of her perplexity I propose: "A kind of unique sex endlessly multiplied".

The archaic objects, proposes A. Green in 1992, are characterized by the confusion between the impulse, the ego and the object, which condition the psychic life of the subject. The ego and the perception-consciousness system become the seat of this confusion, which appears directly determined by the subject's refusal to perceive and represent the anatomical 
difference between the sexes. For Luiza, this neutral sex represents her categorical refusal to appropriate the feminine and maternal interiority. I understand this denial of castration, which allows the differentiation of male and female and makes them complementary, as a creation of a third sex, the neutral sex. In his 1973 article "The neutral gender", A. Green describes a similar reality, only that his theorizing concerns a total object, whereas in Luiza's case it is a partial object. The same reality of denial of castration characterizes the particularities of the way in which the patient positions herself towards me in the analytical setting and from a transferential point of view. It was only after several years of analysis on the couch that the regression induced by the method allowed, thanks to a dream scenario, the identification of the type of archaic involved in this treatment. Before recounting the dream that was a key moment in the evolution of the transference-countertransference relationship and the mechanisms of release, I would like to remind you that "primary anality" (A. Green, 1982) is the main feature of the way borderline patients operate. In contrast to the first anal phase, signalled by K. Abraham as a line of separation with psychosis, in primary anality the mechanisms of expulsion go beyond the anal erogenous zone and invade the Ego as an agency. This regressive dynamic will have multiple consequences, such as the demand for character positions and the repetitive tendency to discharge the pulsational excitation inside (in) or outside (out).

In the case of my patient the discharge is done almost exclusively inside the body, producing various somatic symptoms. As A. Green (1982) pointed out, primary anality is the first attempt to master and control the archaic, which cannot be accurately identified and is most often expulsed. This is the reason why the primary anal conflict is, paradoxically, both the archaic and the defence against the archaic. But first of all, the primary anal conflict represents a resistance to the offense that constitutes the existence of the unconscious and the impossibility of controlling and mastering the effects it produces. The feeling of omnipotence originating in the hallucinatory satisfaction of desire and unfolding freely in the primary processes, in this case makes what the analyst says unable to counterbalance the inner action of the object, which besieges the Ego and persecutes it permanently. We know that in the archaic perspective both terms, doing and talking, are mixed and equivalent, word becoming through animistic regression act, action. The dream that Luiza will tell me occurs during a period of double regression, of the patient and of me as an analyst, a regression favoured by a series of interpretations in transference, which ended by highlighting the main point of impact, an archaic oral-anal fixation, determinant in the expression of the patient's pathology.

In a dream Luiza perceives "the dream Ego", looking for a place to live and to take shelter. When the right house is found, the dream ego merges with her and someone, a neutral but benevolent invisible presence, encourages her to visit the basement. A substance of curious consistency, resembling diarrhoea, runs down in rivulets along the walls. The smell that is emanated is unbearable. The patient concludes that the basement would correspond, on the 
upper floor, with the bathroom of the house. The flow of diarrhoea never ceases, but its appearance changes with time, and begins resemble vomit more and more. Although "disgusted", Luiza tells me that she couldn't help but dip her forefinger into the substance that continues to flow along the walls, curious to discover whether it is faces or vomit. The gesture made in the dream awakens her, but the unpleasant sensation of her finger remaining damp and foul-smelling persisted all day. This is why she felt compelled to wash her hands from morning to evening, hoping to finally get rid of the "faecal-vomit" smell, which did not cease to obsess her. I resume the "faces-vomiting" in the rhythm based on the motif from the sung-spoken stories in children's games. As in the psycho-dramatic technique, I was trying to work the animistic system of infantile magical actions, involved in the sensorial and organic cenesthetic sensations that constitute the core of the hallucinatory motor achievements. "Faeces-vomit" Luiza hums at the same rhythmic pace, repeatedly imitating me with obvious pleasure. And she remembers on this occasion that he never suffered from diarrhoea. She has always suffered from chronic constipation, and no drug helped in evacuating faeces daily. "Faeces-vomitdiarrhoea" Luiza sings again, thus enriching the signifier. These three words reminded her of the distressing period, at the age of 11-12 years, in which anorexia and the newly-appeared symptoms of asthma overlapped and thus required a long hospital stay. Her mother seems to have found the separation very hard. I ask her: "And you?" She replies that she only remembers not understanding why all the adults around her were worried. An incidental idea makes me wonder if this separation could play a role in the fact that her menstrual cycle began shortly afterwards. I answer indirectly, pointing out that 11-12 years was the time when her uncle and aunt managed to "cure" her of anorexia. But this miraculous healing was accompanied, according to her, by an intensification of asthma attacks. I try by my intervention to clear the "transitional" model of psychic functioning described and called "oroanality" by A. Green (2002) from the archaic register. It is a model that only the regressive dynamics introduced by psychoanalytic treatment can highlight, characterized by the displacement of an oral digestive problem in the register of a respiratory problem. In my opinion, the psychopathological context in which this patient's care took place illustrates not only the prevalence of narcissistictype defence mechanisms, but also the pulsional foreclosure, in particular of destructive impulses (A. Green, 2002). This allows us to understand how and why, in this patient's case, somatic diseases could be substituted for the different mechanisms of mental defence. On the technical level, in order to obtain a certain therapeutic efficiency, I proposed to the patient transference interpretation, whose dynamics included the key signifiers of the type "colony", "stingy" (which implies the cenesthetic sensation of tightening), "contraction", "faeces-vomit", in semiotic and semantic registers that allowed the related organic and bodily functions to decondense, to metaphorise and to differentiate. 


\section{The paradoxical actuality of the archaic}

The psychoanalytic cure of Luiza comforts us in the idea, essential for psychoanalytic practice, that the archaic is part of the memory. A memory whose main dimension is presented in the form of an inscription in the body, in the sensoriality and cenesthesia that characterize it, as well as in the language of words originally rooted in flesh, senses and soul. That is why, for psychoanalytic thinking, the archaic represents the "infantile", not as a moment perceptible from a chronological perspective, but as a set of affects and representations that the child inherits from its predecessors. During the psychoanalytic cure the memory of the infant is incarnated in the transference, an oedipal passion that, through this actualisation, became the repetition without memory of the archaic. The person of the psychoanalyst, a support for the mechanisms of projection and identification of the patient, at the same time becomes the target of a negative hallucinatory process, which absents him. P. Fédida (1995) developed the idea that this negative action is the basis for the regression in the classical cure. Only in this way, meaning absent as a real person, the psychoanalyst can metaphorically represent "the place of the stranger", an animistic action that summons and resurrects the oedipal objects of the past into the present, as if by magic. But despite the fact that the human psyche is definitely marked by its archaic period, the clinical material revealed by regressed analysands cannot give us a true image of the very distant past, because the return of the repressed always brings with it the layers of the different periods that it crossed and covered. Consequently, what returns to the surface is not a sure witness to individual prehistory, but rather a composite product, each period of life traversed bringing changes to the archaic object found.

The example is given by Freud himself, who enriched metapsychology by proposing a second topic. I make the theoretical addition that it did not replace the first topic, but supplemented it with a new point of view. In this perspective, the Superego paradoxically becomes the agency which, although the last to emerge in the constitution of the psychic apparatus, is at the same time the most profoundly marked by the existence and presence of the archaic. According to the metapsychological hypothesis, the Superego as an instance results from the division of the Ego, which in turn results from the differentiation of the Id under the influence of external reality. I would like to remind you that the Superego appears after the separation of a part of the Ego, but not by an ascending process, but by a path that involves a retroactive trajectory, because the part of the Ego that becomes the Superego will influence both the Id and the Ego. In conclusion, the Superego is constituted by rooting itself in the Ego and in the Id, which is why the archaic manifests itself in the Superego during the analysis of a subject. To the extent that the child's Superego is not formed on the parent's model, but on the parent's Superego's model, it represents the most metaphorical agency. It is also a contradictory structure, being linked to the body through the Id, and at the same time grafting on the elements most remote from the sensory and corporeal sensuality, that is to say on the trans-generational images. 
This is why the Superego allows us to seize the presence of the archaic, where least expected. A paradoxical report that the Superego maintains with the most metaphorical part that links the child's Ego to the images of parents, through the Ego Ideal. The Superego-Ego Ideal coupling helps us understand how and why a single agency of the psychic apparatus ensures two types of relation to the object: the internalization (related to the Super) and identification (related to the Ego Ideal). The purpose of the psychoanalytic process then becomes the possibility of linking the archaic into the Superego and the Ego Ideal. In this sense, I remember the dream of transference Luiza had, which illustrates the process of internalizing her mother's body, starting with the voice, a fundamentally over-determined sensory element in the treatment, which allowed me from that moment on to establish a classic analytical setting. Only after several years of analysis, this internalization can be dramatized in scenarios related to infantile sexual theories and the family story, through the dramatization of dream work. Luiza shows up breathless to the session, telling me that she had run for fear that she would not have enough time to tell me the dream she had in the morning. She immediately added that she had actually forgotten the dream itself, but that she remembered what it had made her think about when she woke up.

As she suddenly stops talking, I ask "What?" "Of a television series titled "Lost". Without knowing, the characters in this TV series were related to each other and did not discover their kinship until much later, after... I repeat, as a question: “After?" Luiza falls silent again and responds with a sudden whisper that the title "Lost" reminds her of the panic attacks she has when driving, when she gets lost at night and no longer knows where to go. While describing in detail her panic attacks and the circumstances in which they take place, I remind myself of what she had told me in one of our preliminary meetings about a grandmother on her father's side, from "Russia, Bulgaria, or maybe Romania", who died before she had a chance to know her. Surprised by the violent reproaches abruptly uttered by Luiza against her mother, who from "pure selfishness" prevented her from approaching her father's family, I remember then the question I had formed during the preliminary meetings, without asking the patient out loud: "Why out of the three names given by the secretariat of the Institute of Psychosomatics had she chosen to speak to me". This time it was accompanied by the answer that came as an echo of the affect expressed by Luiza: "In the unconscious hope that the meaning suggested by my name and surname will bring back to life the loved ones known/unknown, lost or disappeared". Although silent, the construction formulated in my inner speech helps Luiza remember the "forgotten" dream: She was at home, in the room she had occupied throughout her childhood and adolescence. A feeling of panic encompassed her at the sight of the "blister" ("cloque"), which appeared around her ankle and swelled before her eyes. In the whitish liquid that filled it there was a "colony" of small jellyfish, which "multiplied ceaselessly". Before she had time to scream for help, the blister broke, and a barrage of tiny jellyfish invaded the floor. The nightmare woke her up suddenly, but Luiza says with a deep breath that it took her a long 
time to calm down. She added, puzzled, that she found in this nightmare an uneasy, worrying familiarity, which she could not identify. "Like a word I have on the tip of my tongue, but I can't quite find". "A word such as a colony?" Amazed Luiza responds: "Yes it could be, but why a colony?" I answer: "For the rabbit-children colony of your father and for the colony of school children present in the collectives you supervised with your mother during adolescence". I used the significant "colony" in order to inscribe the baby-jellyfish, created by the infantile sexual theory of the dream, both in the erotic relationship with her father and in the constraint relationship, coloured by erotic-mania, towards the mother.

Luiza responds visibly dissatisfied: "Yes, and so what ...?" "Then it would seem that in the dream you are pregnant". In French slang to be "en cloque" means to be "pregnant". From the countertransferential point of view I had the impression that this "forgotten dream" and found again opened the transference of the patient to a trans-generational dimension, which in turn allowed for a permeability to infant sexual theories generated by the "original fantasies". Here I make the hypothesis that the generalized excitement that constituted the patient's way of life from the first moments of existence, and that was downloaded since then in the repetition of the corporeal and/or somatic symptoms, became transferable, therefore interpretable, only after the experience shared with the physiotherapist and in the same time lived, understood and worked through with me in the psychoanalytic process. My interpretation: "So the second session, which you refuse in psychotherapy, you do with the physiotherapist", allows the patient to finally represent a triangular relationship of a homosexual type, and opens the regressive path of the original fantasies, here the seduction of the adult child. The hyper-condensed polysemy of sensory and cenesthetic sensations, felt when material reality reinvested the corporeal inscription of the archaic of original fantasies, translates by the manifestation of infantile sexual fantasies experienced in the body at a preconscious level, perceived on the screen and only then barely represented in the thought. At the beginning of psychic treatment Luiza complains that she feels "torn" between all the specialist doctors in charge of her, and her many symptoms, and begs me to "unify" her. I have heard and understood the patient's request as a necessity to differentiate the narcissism-dependent autoeroticisms, as well as the partial impulses under the influence of the genital current. The transference dream the Lolita-Witch, which reoriented the cure from psychotherapy to psychoanalysis, represents this moment of pulsational transformation that the patient's speech in the session faithfully illustrates. Moment from which to speak, to recount, no longer represents a narcissistic type of action to contain, rather than to elaborate. A "narrative-recitative" discourse to which the counter-transference framed space allowed to transform sufficiently, in order to carry in transfer suppleness and capacity for associative psychic play. As for the dynamics of the partial impulses that required reunification under the direction of genitality, the moment that induced the beginning of the process of change is rooted, in my opinion, in the proposed interpretation of the patient in which I resumed and included the significant "stingy" already present in her speech. My interpretation: "maybe 
because you do with the vagina as you do with your anus", establishes a vagina-anus connection that allows the significant "contracture" ("grippe") to migrate, to move and, in this way, to metaphorize different areas of the body and somatic functions. I find it very interesting to point out that after this first vaginal-anus connection, which shows the interest in summoning the cloacal theory, the significant "grippe-contracture" modifies the asthmatic manifestations of the patient.

In one of the sessions Luiza announces, as if it were matter of fact, that her pulmonologist was surprised to find that her asthma attacks were increasingly rare and that her respiratory capacity had improved. From a meta-physiological point of view, I explain this improvement through the mechanism of moving from one conflict sector to another conflict sector. Shortly before, an interpretation was made in a psycho-dramatic register. We chose this counter-transferential expression path to highlight the affect, and thus to inscribe the transformation process that took place in an inter-subjective dynamic: "Ah, finally a novelty! Your lungs are no longer stingy (grippe-sous)". When I propose this interpretation, I hypothesize that the same pulsational action of "grippe-contracture" presided over the asthmatic manifestations that Luiza presents, and that in this way the connection established by my interpretation between these three bodily spaces, lung-anus-vagina, and their functions will allow a double operation to decondensate and move the impulse energy of aspiration inspiration and expiration. My hypothesis is formulated based on the fact that when Luiza complains about all the diseases she suffers from since early childhood, her speech that is repeated from one session to another establishes them in the position of signifiers. Signifiers whose "heterogeneity" (A. Green, 1971) includes different states of the body and its somatic functions in their polysemy. Therefore, in general, the transfer addressed by the patient to the psychoanalyst resonated in its countertransference, creating a type of communication dependent on the psychoanalyst's own regression modalities. This is an ability acquired in her own analysis, the only ability to allow the patient to face the archaic aspects of her psychic life. This transference-countertransference phenomenon is directly dependent on language's ability to lend itself to unconscious labour. I recall here that Freud was the first to emphasize the ability of language to regress, an ability that makes it become the faithful performer of psychic regression in the psychoanalytic cure. The historical basis of language allows it to decompose, to dissolve its logical oppositions and to return to the archaic stage of "raw material". Archaic, because in this primitive language found in healing, words are used without regard to the oppositions that regulate their meanings. The "archaic" adjective attributed to this language is justified by the fact that determining the meaning of words is not about verbal oppositions, but about image and gestural motility. And since the ancestral core of the language also contains the component of the action and the equivocity of the meaning, tongue and language can be prepared, in the moment of transferential regression, and in the hallucinatory accomplishment of the act (so that at the beginning of the beginning to say was the equivalent of to do) also for 
deformation, a mechanism which ensures the concealment of the content due to the equivocity of the meanings. This is why it can be said that the archaic represents the memory of the past in the present, precisely through this dimension of inscription in the body and in its sensorial and cenesthetic sensations.

Through transfer the analyst awakens the memory of the child, and in this way the passion for oedipal objects is repeated in action (agieren), a repetition that, if not interpreted, prevents remembrance and perlaboration. Because only the patient's speech can allow us to penetrate and understand the obscure relationships that words maintain with the unconscious. To the extent that words are important in their ability to attract, capture and transform the primary process into secondary process. This despite the fact that only the equivocal words are retained by the labour of mourning, because they alone can present an anodyne figure to censorship, while their visible significance allows the hidden satisfaction of prohibited impulses. Freud drew attention to the fact that the drive/impulse "manages to find satisfaction by shifting its purpose from the tendentious meaning of the equivocal word" to the "innocent" meaning.

After the spring vacation Luiza complains about new symptoms. Especially of a "noise in her ears" that resembles a kind of muffled whispering. The medical consultant assured her that it was nothing serious, and explained that the disturbing noise was caused by the "rubbing of two hairs", she tells me that she forgot their name, which got "stuck" and that now there was nothing else to do but wait for them to become unstuck. She asked me if the ear canals are anatomically similar to the genital system's tubes. I ask her if she thinks that the separation caused by the vacation could be playing a role in the appearance of this new symptom. Luiza seems surprised: "Why?" "Maybe because words are the instrument of psychoanalytic treatment and their perception is made through hearing, which involves the activity of the ear". Luiza tells me that she doesn't see the connection, but as I spoke to her she remembered a Japanese cartoon, a "manga" read during the holiday that scared her greatly. The manga featured fish in the phase of genetic mutation, which reproduced at an accelerated rate in order to "colonize" humans, to transform them into intermediate creatures, that is, "neither alive nor dead". She adds that she doesn't understand why kept her up all night. "Did you perhaps think that my words could colonize and transform you into such an intermediate creature, neither boy nor girl?" I try through my interpretation to move the vital register to the register of sexuality. Luiza tells me that she doesn't understand anything I'm saying. All the more so as I should already know that sexual difference makes no sense to her.

Although my attempt to put the significant "colonize" (narcissistic plan) in relation to the significant "colony" (sexual plan), this seemingly rejected by the patient, the meaning of my interpretation appears unconsciously perceived: "It certainly has no relation, but the fish that multiplied made me think how happy I was all my childhood, to have a mother without a 
life partner. You realize how much the poor children who have two parents have to endure their sexual relationships for years". The pulsational tension created by this connection I make between "colonizing" and "colony", terms of which the verb appears to me as more regressive and deadly than the noun, evokes the existence of an archaic primitive scene figured but immediately denied by the mechanism of transformation contrary to affect.

"Neither boy nor girl", my attempt to put these two signifiers in the perspective of the double dynamics of the Oedipal Complex, signifies the impossibility of the patient to constitute a functional psychic bisexuality. Because, as the psychoanalytic experience proves daily, psychic bisexuality is constituted by the fantasmatic acquisition of the other sex, which the subject does not have in reality, but which can be imagined within the oedipal triangle. The double aspect of the Oedipal Complex, positive and negative, is determined by the double male and female identification that organizes access to the sexual difference and complementarity, in the case of a subject whose identity is well established in reality. I wondered and kept wondering if the malformation that Luiza suffered from birth, anatomically present through a double vagina and a double uterus, did not disorient her psycho-sexual destiny, if this caused male and female identities to lose their complementary dynamic of opposites, turning into contradictory categories. I hypothesize that from here stems both the narcissistic character of the patient's interests and her categorical refusal to accept representing the difference between the sexes. A means to exist in relation to reality that determines even the organization and expression of abstract functions of judgment, reasoning and constitution of thought in Luiza. I would like to emphasize here that the language and syntax used by the patient in the speech during sessions become, in their turn, a faithful illustration of these difficulties she encountered during the process of subjectivization. For example, the repeated use of the negative conjunction "neither ... nor" resumes in language this deadly disposition induced by the immobility of the negative properties by the continuous establishment of a dynamic of desubjectivization. Once they are "intruded" on by fish that multiply "ultra-fast" (in this case we are witnessing a monstrous primitive archaic scene), people are no longer "completely alive or dead". Like "sex toys" that are "neither phallic-masculine", "nor round-feminine" - the two oppositions are excluded to constitute an irrepresentable neutral multiplied to infinity. "Neither... nor" the same split denial probably stopped Luiza's thinking process when she tried to write her university thesis. Despite her major inhibition, the professor responsible for the work allowed her to obtain her PhD by suggesting she establish a bibliography of research papers written by different authors on the subject she was passionate about (operative thinking?).

Luiza accepted the proposal, but felt "profoundly humiliated". She could not evoke the subject with me in a session until after years of psychoanalysis. Like the feeling of shame that hid, with increasing difficulty over time, repressed envy, fury and narcissistic anger. These 
affections often encountered in borderline states signified, from a meta-psychological point of view, the regression of the Ego Ideal to the archaic Ego Ideal. "You do not give, but you do not take", as I had interpreted almost prophetically in a session at the beginning of treatment. It remains to be hoped that the psycho-affective and intellectual immobilization, of which Luiza was and still is a prisoner, could be modified and transformed slowly, due to the psychoanalytic process established and sustained by the method, by the setting and by transference.

\section{In conclusion}

Unlike all other forms of therapy, the psychoanalytic cure, whose only and main treatment tool remains the word, mobilizes archaic aspects among the different registers of the language. The dynamics in which the regression of the language can accompany and express the psychic regression, in the most subtle and profound shades. Due to the heterogeneity of the signifier, the language used in transference-countertransference communication allows the analyst and the analysand to perceive and represent the essence of the unconscious psychic tissue in the psychoanalytic process. The word, which, as any psychic action, cannot escape the domination of the all-powerful principle of pleasure-displeasure, becomes in this perspective the fundamental element of investigation of the method. A method of free association that allows the transference, an intra-psychic and inter-subjective phenomenon, to reveal the archaic emotional background constituted by the child sexual experiences re-actualised in the transferential relationship. The "infans", the child before the acquisition of the language, can be found due to the common regression of the analysand and the analyst from the representation of the word to the representation of the object, that is to say, through the process of figurability induced by the countertransference of the analyst. An indisputable economic determinism presides in this regression of the language and of words, from the representation of the word to the representation of the objects in psychoanalysis sessions, thus defining the way in which different means of communication, from the most sophisticated to the most primitive, extralinguistic (various forms of sensoriality, gestures, sensations, emotions, feelings, psychic, bodily and/or somatic feelings) can be found, built or reconstructed during psychic treatment. In accordance with the law of deformation, which dominates unconscious psychic life, these representations of the object are in an indirect and unpredictable relation with the affective and emotional contents caused by life events. Psychoanalysis then appears as the only method able to capture in the grasp of the patient-analyst relationship, and to represent this fundamental relationship that the archaic maintains with the historical reality and events, which are the basis of the existence of the human subject. A vital issue emerges, in my opinion, from this context.

Why does the need to approach the archaic aspect of the analytical relationship represent a decisive mechanism in the changes and transformations induced by the psychoanalytic 
protocol? This is an indispensable question for deepening the modalities of evolution of the psychoanalytic technique and of the possibilities to apply it to the variety and gravity of current psychopathological structures. To the extent that the pathogenic regression states of patients do not allow an exact reconstruction of the elements in which the mental difficulties of which they suffer originate. And this is precisely because the origin is different from the archaic. An archaic that continues to produce sense in the present, and through the most strange and unexpected clinical forms thus summoned, forces psychoanalytic practice and its practitioners to adapt to modernity.

\section{REFERENCES}

ABRAHAM, K. (1907-1925). Oeuvres complètes. [Complete works] Payot, Paris, 1966, p. 362.

ADOMNICAI, I. (2004). Corps malade et adolescence. [Sick body and adolescence]. In Press, Paris, p. 266.

AISENSTEIN, M. (2002). La tombe des lucioles. [Grave of the fireflies] In Rev Franc Psychosom 22: 39-44.

FAIN, M. (1971). Prélude à la vie fantasmatique. [Prelude to fantasmatic life]. In Rev Fr Psychanal 35: 291-364.

FEDIDA, P. (1995). Le site de l'étranger. [The site of the alien] PUF, Paris, p. 311.

FREUD, S. (1914). Pour introduire le narcissisme. [On Narcissism: An Introduction] In La vie sexuelle. PUF, Paris, 1969, p. 14.

FREUD, S. (1923). Le Moi et le Ca. [The Ego and the Id] In Essais de psychanalyse. Payot, Paris, 1981, pp. 219-262.

FREUD, S. (1937). Constructions dans l'analyse. [Constructions in Analysis] In Resultats, idées, problèmes, II. PUF, Paris, 1985.

GREEN, A. (1973). Le discours vivant. [The Living discourse] PUF, Paris, p. 364.

GREEN, A. (2002). La pensée clinique. [The clinical thought] Odile Jacob, Paris, p. 358.

MARTY, P. (1980). L'ordre psychosomatique. [The psychosomatic order] Payot, Paris, p. 299. 
MCDOUGALL, J. (1989). Théâtres du corps. [Theatres of the body] Gallimard, Paris, p. 220.

SMADJA, C. (1993). A propos des procédés autocalmants du Moi. [On the self-calming processes of the Self] Rev Franc Psychosom 4: 9-25. PUF, Paris.

SZWEC, G. (1993). « Les procédés autocalmants par la recherche répétitive de l'excitation. Les galériens volontaire ». [The self-calming processes for the repetitive research of excitation,] Rev Franc Psychosom 4: 51. PUF, Paris, p. 51. 